\title{
ARMAND BOREL
}

\author{
GOPAL PRASAD
}

Borel first visited India in 1961, when he gave a series of lectures on compact and noncompact semisimple Lie groups and symmetric spaces at the Tata Institute of Fundamental Research (TIFR) in Bombay. His course introduced the theory of Lie groups and geometry of symmetric spaces to the first generation of mathematicians at TIFR, who in turn trained the next generations in these areas. Having joined TIFR in 1966, I belong to the second generation, and so I owe a considerable debt to Armand Borel for my education in the theory of Lie groups and even more directly in the theory of algebraic and arithmetic groups, which I learned from his excellent books and numerous papers on these two topics.

Subsequently, Borel made many visits to TIFR and other mathematical centers in India. He was deeply interested in the development of mathematical institutions in India and helped several of them with his advice and frequent visits. For his contributions to Indian mathematics, he was made an honorary fellow of TIFR in 1990.

During his numerous trips to India, Armand and his wife, Gaby, visited many sites of historical and architectural interest and attended concerts of Indian classical dance and music. He became fond of many forms of Indian classical dances such as Bharat-Natyam, Odissi, and Kathakkali. Even more so, he came to love both Carnatic (south Indian) and Hindustani (north Indian) classical music. He became quite an expert on the subject and developed friendships with many musicians and dancers from India. He invited several of them to perform in the concert series he initiated and directed at the Institute for Advanced Study, and with Gaby hosted some of them in his house during their tours of the United States.

Indian classical music concerts differ from their western counterparts in many ways. The ones in India often start in the evening and continue until late into the night, with a single vocalist or instrumentalist playing for hours, sometimes solo and sometimes accompanied by a percussion player. This is always an endurance feat, not just for the artist, but for the audience too. Borel attended numerous such concerts and timed his trips to India so that he could attend a major Carnatic music festival held every December/January in Madras. Notable elements of Indian music, as with jazz, are improvisation, melody, and rhythm: the artist never uses a written score during the performance. The artist is simultaneously a composer and a performer. The rhythms involved are intricate and evolving. Borel was an equally enthusiastic jazz and blues aficionado; he frequently went to New York for such performances. It would appear that improvisation and complex rhythms in Indian classical music appealed to him quite naturally.

Borel was an astute observer: he had an uncanny eye for artistic detail and would reflect on the influence of literature and culture on human outlook. Once, at first sight, he pointed to a statue of Ganesha (the Hindu god with an elephant head and human body) in my apartment in Bombay and observed that the trunk was curled

Reprinted from the Notices of the AMS (Volume 51, Number 5) with the permission of the American Mathematical Society.

Gopal Prasad is professor of mathematics at the University of Michigan at Ann Arbor. His email address is gprasad@umich.edu. 
to the right and not, as he had usually seen, to the left - a seemingly obscure fact, most would think. He was delighted to learn, however, that it actually has important symbolic significance. In another, more recent, episode Borel discovered the Harry Potter children's book series by J. K. Rowling. He was greatly enthused by what her books had done to boost the literacy rate of youngsters and captivate their imagination in a time when books face such fierce competition from other media. On July 28, 2003, while already gravely ill, he wrote to Rowling to express this sentiment and to convey his admiration. In his letter he also speculated that the "quickness, cleverness" of even ordinary Indians, and not just his mathematical colleagues, "may be due in part to the fact that they are familiar with stories from great Indian epics Ramayana and Mahabharata from childhood on, in comparison with which our own fairy tales are no match."

Borel told me on more than one occasion that if he had a choice for a second life, he would like to be born a Hindu in India. This would work out well, since Hinduism, like most other religions originating in the subcontinent, propounds the doctrine of Karma and rebirth.

It is well known that Borel was meticulous. (And his stern demand for excellence in all things was exacting. This led to considerable anxiety in many of his colleagues.) His lectures, writing, seminars, summer schools, and trips were minutely planned. For example, before his first visit to Ann Arbor, he consulted his secretary, Elly Gustafsson, who had lived in Michigan for some time. On her suggestion, we went together to see the sculptures of the famous Swedish artist Carl Milles in Cranbrook Academy near Ann Arbor. Despite knowing of his penchant for detail, I was surprised to learn that Borel had not only closely studied the work of the artist before coming to Ann Arbor, but knew exactly how many of his sculptures there were in Cranbrook, and made sure that we saw each one of them before we left.

My First Meetings. In 1972-73, I visited Yale at the invitation of Dan Mostow. This was my first visit abroad, and during the year I went to the Institute for Advanced Study (IAS), Princeton, to spend a weekend with my colleagues V. K. Patodi and R. Parthasarathy. Since Borel had already been an important influence in my mathematical development, I wanted to meet him. Patodi took me to Borel's office and introduced me to him. This happened on a Saturday. I later learned that he reserved Saturdays for writing manuscripts. However, Borel was quite warm and friendly, and we spent about two hours talking. During the discussion at that time, and on numerous subsequent occasions, I got the impression that he expected precision and showed unease in his own characteristic way if the discussion became imprecise or the arguments vague. I spent the next year at the IAS. In large measure it is because of him that I had a very fruitful stay at the Institute then and in my three subsequent year-long visits to the Institute.

During my stay at the Institute, whenever I had a question about Lie or algebraic groups, I asked Borel, and if he did not have an answer right away, he came back within a few days to provide me with a detailed answer and relevant references. Harish-Chandra once told me that whenever he needed a result about algebraic group or needed a reference, he turned to the encyclopaedic knowledge of Borel.

Borel as a Collaborator. Borel was an exceptional collaborator. He was very conscientious, and despite his many commitments, he diligently worked on questions that came up during our discussions and actively took part in writing and revising joint works. 
Even before our collaboration began, I knew that he was an extremely good correspondent who promptly replied to every letter addressed to him. During my stay at the Institute in 1980-81, he told me that he considered it a duty to seriously look into and promptly respond to all mathematical letters he received. The reason for this, as he explained to me, was that S. Ramanujan, the mathematical prodigy, had written about his discoveries to two mathematicians, Henry F. Baker and E. W. Hobson (both of Cambridge University), but neither responded. Had G. H. Hardy, to whom Ramanujan wrote later, also ignored his results and not replied, Ramanujan and his work might have been lost to mathematics.

My Last Meeting. Borel kept himself fit by swimming a mile a day, weighttraining, and bicycling. So the news of his illness came as a rude shock, and I immediately determined to see him. For this purpose, having arranged with Gaby through Lily Harish-Chandra to meet with Borel, I went to his house in Princeton on August 10, 2003, in the evening. Gaby and Borel's daughters, Dominique and Anne, were there. I talked with Borel for some time. He felt feverish and, at his request, I measured his temperature, which turned out to be normal. I asked him if he listened to music, his chief passion besides mathematics. To try to cheer him up, I told him that once the debilitating effects of the radiation wore off, he would be able to resume his normal routine, and I would come back to see him in a month. He commented that I was being too optimistic. Unfortunately, he was proved right, and the very next day I learned from Lily that he had passed away early that morning.

It is a great privilege to have known Armand for thirty years and to have collaborated with him. His passing away is a deep personal loss for me. 
